\title{
Pre-Announcement Effects, News, and Volatility: Monetary Policy and the Stock Market
}

\author{
Antulio N. Bomfim* \\ First D raft: D ecember 1999 \\ This D raft: O ctober 25, 2000
}

\begin{abstract}
I examine pre-announcement and news effects on the stock market in the context of public disclosure of monetary policy decisions. The results suggest that the stock market tends to be relatively quiet--conditional volatility is abnormally low--on days preceding regularly scheduled policy announcements. Although this calming effect is routinely reported in anecdotal press accounts, it is statistically significant only over the past four to five years, a result that I attribute to changes in the Federal Reserve's disclosure practices in early 1994. The paper also looks at how the actual interest rate decisions of policy makers affect stock market volatility. The element of surprise in such decisions tends to boost stock market volatility significantly in the short run, and positive surprises--higher-than-expected values of the target federal funds rate--tend to have a larger effect on volatility than negative surprises. The implications of the results for broader issues in the finance literature are also discussed.
\end{abstract}

JEL Classification: G 14, E44, C32

Keywords: Uncertainty, Information, Announcements, Expectations, GARCH, Risk

$\bar{*} \bar{M}$ onetary and $\overline{\text { Financial }}$ Market Analysis, Mail Stop 74, Division of Monetary Affairs, Federal Reserve Board, Washington, D C, 20551, abomfim@ frb.gov, Tel.. (202)736-5619. I have benefitted from conversations with Vincent Reinhart and from comments provided by Michael Boldin, Bill English, Brian Sack, and seminar participants at the Federal Reserve Board and the January 2000 Meeting of the American Economic Association. Ian Anderson provided excellent research assistance. The opinions expressed in this paper are not necessarily shared by anyone else in the Federal Reserve System. 


\section{Introduction}

A growing number of papers in both the economics and finance literatures focuses on the effect of economic news on asset returns. Nonetheless, there seems to exist a wide gap between these two literatures. First, while economists have tended to focus on the impact of new information on the levels of asset returns, their counterparts in finance have emphasized the relationship between news and the volatility of returns. ${ }^{1}$ Second, although the majority of papers in the economics literature have zeroed in on the effects of monetary policy surprises on various asset markets, only a handful of studies in finance have actually focused on the impact of monetary policy news on market volatility and the news-volatility literature has generally not distinguished between anticipated and surprise announcements. ${ }^{2}$ This paper attempts to bridge this existing gap between economics and finance. In particular, I examine how the element of surprise in one particular type of news-announcements of short-term interest rate decisions made by the Federal O pen Market Committee--affects the volatility of the stock market in the short run.

${ }^{1}$ Representative papers from the finance literature include Andersen and Bollerslev (1998), Jones, Lamont, and Lumsdaine (1998), Berry and Howe (1994), Mitchell and Mulherin (1994), Ederington and Lee (1993), Cutler, Poterba, and Summers (1989), Roll (1988), and many others. Recent papers from the economics literature include Bomfim and Reinhart (2000), Kuttner (1999), Roley and Sellon (1998), Thornton (1998), and Reinhart and Simin (1997).

${ }^{2}$ Recent exceptions from the finance literature include Chen, Mohan, and Steiner (1999), who examined the effect of discount rate decisions on stock market volatility, and Andersen and Bollerslev (1998), who examined the effects of several economic announcements in intraday data, including the release of the minutes from FO MC meetings. Previously, Castanias (1979) had also examined the relationship between discount rate decisions and the volatility of stock returns. 
I look at the relationship between monetary policy and daily stock market volatility from two vantage points: days around regularly scheduled meetings of the Federal 0 pen Market Committee (FOMC)--the main monetary policymaking body in the United States-and days of actual policy decisions involving the target level of the federal funds rate. Along the first dimension, I examine whether the existence of regularly scheduled policy meetings per se has a measurable effect on stock market volatility. ${ }^{3}$ Judging from reports in the popular press, the answer to this question would be yes, as evidenced, for instance, by numerous news stories associating days of relative calm in the markets with upcoming FOMC meetings. ${ }^{4}$ I find statistical support for such headlines, but only after taking into account the effects of changes in the monetary policy news arrival process over the years. In particular, such "pre-announcement" effects are present only over the past five years or so, a period when the majority of policy decisions have actually been taken at the FO MC's regularly scheduled meetings.

Turning to the days of actual policy decisions--regardless of whether they were announced on regularly scheduled meeting days--I find some evidence that such decisions tend to boost volatility in the stock market. As suggested by theory, the effect of policy decisions is greatest if I exclude those decisions that were fully anticipated by market

${ }^{3}$ Since 1981, there have been 8 regularly scheduled meetings of the FOMC per year, generally with 6 to 8 weeks between meetings. Meeting dates for each year are announced to the public during the second half of the previous year.

${ }^{4}$ For instance, in the morning of August 24, 1999--a policy meeting day--a CNNfn news wire noted that trading in the stock market was "very quiet ... amid anticipation that the Federal Reserve would raise interest rates in the afternoon." 
participants. The results also suggest that positive surprises--higher-than-expected values of the target federal funds rate--tend to have a larger effect on volatility than negative surprises, consistent with both the leverage and volatility-feedback hypotheses studied by Black (1976) and French, Schwert, and Stambaugh (1987), respectively. On the whole, I find that, from previously depressed levels the day before an FO MC meeting, a surprise increase in the target federal funds rate at that meeting boosts market volatility to well above typical levels.

Besides identifying monetary policy announcements as an important source of shortrun volatility in the stock market, this paper also addresses broader issues in the finance literature. First, by looking at policy decisions that were taken both at scheduled FOMC meetings and on other, ad-hoc, days, I am able to distinguish whether the markets respond differently to scheduled versus unscheduled announcements. ${ }^{5}$ Second, by focusing on days before regularly scheduled meetings, I examine a topic that has received surprisingly little attention from the literature: The question of whether the imminent release of marketrelevant information has a discernible impact on the stock market. ${ }^{6}$ Lastly, the findings call attention to a well-known result that is often overlooked in empirical studies of the

${ }^{5}$ Two recent empirical papers that also look at this issue include Andersen and Bollerslev (1998), who briefly discuss the potentially different effects on volatility of scheduled versus unscheduled announcements, and Li and Engle (1998), who estimate the degree of persistence heterogeneity regarding the two types of announcements in the Treasury futures market. Kim and Verrecchia (1991) use a theoretical model to examine the effects of scheduled and unscheduled announcements on market participants' information gathering efforts.

${ }^{6}$ Jones et al. (1998) examine a similar question in the U.S. Treasury securities market, Li and Engle (1998) analyze the Treasury futures market, and French, Leftwich, and Uhrig (1989) look at the agricultural futures market. 
relationship between news and volatility: the prediction from theory that it is only the surprise element of any piece of news that should affect asset prices. Indeed, perhaps the failure of many papers in the finance literature to detect a significant relationship between market volatility and the arrival of new information stems from the inability to appropriately distinguish what was truly new in the information released from what had already been built into market prices. ${ }^{7}$

The paper is organized as follows. The next section provides a brief description of the news arrival process for monetary policy, i.e., of how monetary policy decisions have been released to the public over the past decade. I also discuss the theoretical implications of recent changes in the news arrival process for the way the markets react to policy announcements. Section 3 describes the empirical framework that is used to test such implications and compares it to methodologies used in much of the economics and finance literatures to examine the markets' response to economic news. The data set used in the empirical analysis is described in section 4 , which also discusses the derivation of the marketimplied policy expectations measure used throughout the paper. Section 5 discusses the results, and section 6 concludes.

\section{The N ews Amival Process: Public Release of Monetary Policy Decisions}

My focus is on decisions involving the target level of the federal funds rate, the main monetary policy instrument in the United States. Such decisions have been relayed to the

${ }^{7}$ Papers that report only a weak relationship between market activity and news include Roll (1988), Cutler, Poterba, and Summers (1989), Mitchell and Mulherin (1994), and Berry and Howe (1994). 
public primarily in two ways. ${ }^{8}$ Until the end of 1993, the Federal Reserve "announced" its intentions regarding the target rate through the size and type of open market operations conducted by its trading desk in New York. ${ }^{9}$ As a result, given that most decisions on the target rate were taken in the afternoon, after the federal funds market was virtually closed, there was usually a one-day lag between the decision and the "announcement." All that changed in February of 1994, when the FO MC adopted its current practice of issuing formal press releases on the same day a decision to change the target rate is made. Consequently, the lag between decisions and announcements no longer exists.

The timing of policy announcements has also changed since February 1994. Between June 1989 and D ecember 1993, only a relatively small proportion (24 percent) of all decisions to change the target fed funds rate were taken on regularly scheduled policy meeting days. Since then only two such decisions have been taken outside of scheduled FO MC meetings, with 85 percent of all policy actions between February 1994 and D ecember 1998 actually taken and formally announced on meeting days.

$\mathrm{N}$ ews A rrival and $\mathrm{M}$ ark et $\mathrm{V}$ olatility. In thinking about the potential channels through which monetary policy affects stock market volatility in the short run, finance theory and existing empirical work involving the Treasury securities and futures markets suggest two possibilities. First, there is the potential for pre-announcement effects, the first leg of a

${ }^{8}$ Bomfim and Reinhart (2000) provide a detailed discussion of the disclosure practices adopted by the Federal O pen Market Committee over the 1989/ 98 period.

${ }^{9}$ Feinman (1993) discusses the types of open market operations used and their signaling content. 
phenomenon that Jones et al. (1998) dubbed the "calm-before-the-storm" effect. Jones et al. find that conditional volatility in the Treasury market tends to be lower in the days leading up to releases of major economic data--the "calming" or pre-announcement effect--and then higher on the day of the announcement itself--the "storm" or news effect. Indeed, such phenomenon is routinely reported in the financial press, and is also supported by studies of other financial markets (Li and Engle, 1998, and French et al., 1989). Thus, in examining the potential link between market volatility and policy decisions, this paper starts out by looking at the question of whether monetary policy decisions can be linked to statistically significant pre-announcement effects in the stock market.

The second channel through which monetary policy decisions potentially affect market volatility relates to the nature of the decision itself. For instance, the announcement of the policy decision may reveal new information not previously incorporated into asset prices and volatility may rise while market participants' process the newly received information (see, e.g., Harris and Raviv, 1993 and Varian, 1989). I shall call this the "news" effect. Note that while the pre-announcement effect is, by definition, independent of the policy decision that is ultimately announced, the news effect is intimately tied to it. In particular, close scrutiny of the news effect should help determine whether monetary policy decisions constitute fundamental news not previously built in into stock market prices or whether they are viewed as a reaction to information about the economy that was already in the public domain. ${ }^{10}$

${ }^{10}$ Several studies in the economics literature detect little or no effect of monetary policy decisions on the short-run behavior of the stock market--see, e.g., Bomfim and 
T estable Implications. Given the changes in the monetary policy news arrival process described in this section, and based on the theoretical considerations just discussed, this paper formulates two working hypothesis regarding the effect of the monetary policymaking process on the short-run volatility of the stock market. To the extent that FOMC meeting days are viewed by market participants as days of major economic news, they should leave an imprint on market volatility, and such imprint should be particularly noticeable in the post-1993 sample, when most policy decisions were actually made and announced on FOMC meeting days. In addition, to the extent that policy decisions affect volatility, it is the element of surprise in such announcements that should matter most. Accordingly, failure to distinguish between anticipated and unanticipated policy decisions would tend to bias the news effect on volatility downwards. Below I describe a modeling framework that allows for formal testing of these theoretical implications.

\section{A Model of Volatility with Announcement Effects}

The empirical model is an extension of the work of Jones et al. (1998) and Andersen and Bollerslev $(1997,1998)$. In particular, in its general form, the model is characterized by the following set of equations:

Reinhart (2000) and the references therein. The scope of those studies, however, was limited to first-moment considerations--policy effects on the level of stock returns--while implicitly assuming that the second moment--the variance of stock returns--remained constant. 


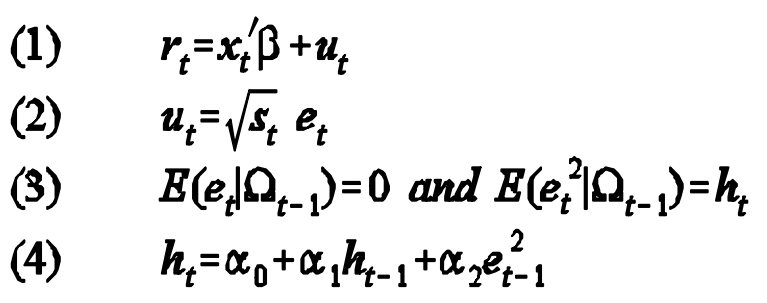

Equation (1) describes the evolution of stock returns, $r_{t}$. Accordingly, the conditional mean of daily stock returns is given by $\mathrm{x}_{\mathrm{t}}{ }^{\prime} \$$, and $\mathrm{u}_{\mathrm{t}}$ captures the unpredictable movements in daily returns. As shown in equation (2), these movements have two components: (i) a potentially non-normal stochastic element, $e_{t}$, with time varying conditional heteroskedasticity $h_{t}-S_{t-1}$ in equation (3) denotes the information set--and (ii) a deterministic scale factor, $\mathrm{s}_{\mathrm{t}}$, which provides the main channel for days of policy announcements to have a separate effect on volatility. Following Bollerslev (1986), e is assumed to follow a GARCH(1,1) process, as in equation (4).

Equations (2) and (3), along with the definition of $s_{t}$, imply that the conditional variance of $\mathrm{u}_{\mathrm{t}}$ is given by:

\section{(5) $\quad E\left(u_{t}^{2} \mid \Omega_{t-1}\right)=s_{t} h_{t}$}

which in turn implies that return volatility is greater than would be suggested by a simple GARCH $(1,1)$ model on days when $s_{t}$ is greater than one.

Specializing the model. As noted above, one of the issues I examine is whether days around regularly scheduled FO MC meetings significantly affect market volatility. A simple specification for $\mathrm{s}_{\mathrm{t}}$ that would be useful in this context is given by: 


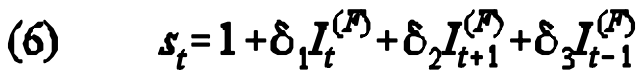

where $I_{t}^{(F)}$ is a dummy variable set to one on days of regularly scheduled policy meetings and zero elsewhere. For instance, if the empirical results were that ${ }_{1}{ }_{1}$ is significantly greater than zero, that would suggest that volatility is boosted on days of regularly scheduled FO MC meetings. Likewise, a finding that ${ }_{2}$ is negative would be evidence of the preannouncement effect.

It is straightforward to see that equation (6) can be modified to address the other questions posed by this paper. Indeed, in the next section I shall rely on a dummy variable that is set to one on days of announcements that were not fully anticipated by the markets and zero on all other days. To sum up, the empirical framework is such that the conditional volatility of stock returns is explicitly modeled and estimated jointly with the conditional mean specification. More important for the purposes of this paper, the model allows for an explicit channel for days of policy announcements and days of policy meetings to affect volatility.

Comparison to other empirical studies of announcement effects. The model presented above can be thought of as more general version of a basic framework used in a growing number of studies in the monetary economics literature. ${ }^{11}$ These papers essentially follow an eventstudy approach, in that they are mainly concerned with measuring the financial markets' reaction to monetary policy actions. At the heart of the event-study approach is the

${ }^{11}$ Examples include the papers listed in footnote 1. 
estimation of equations like (1), where the variance of $u_{t}$ is either assumed to be constant or not modeled explicitly. The vector $\mathrm{x}_{\mathrm{t}}$ is supposed to capture a measure of the policy action, and the estimation sample comprises only days of policy action. A typical example is the early work of Cook and Hahn (1989), who examined the Treasury securities market's reaction to monetary policy actions. Cook and Hahn used ordinary least squares to estimate equation (1) with $\mathrm{x}_{\mathrm{t}}$ ' defined as $[1,) \mathrm{f}_{\mathrm{t}}$ ], where $\mathrm{f}_{\mathrm{t}}$ denotes the target federal funds rate, and $\mathrm{r}_{\mathrm{t}}$ is redefined to denote the change in a given Treasury yield.

More recently, Roley and Sellon (1998) also estimated a particular version of equation (1), both for the Treasury securities and stock markets. In addition to the days of actual changes to the target fed funds rate examined by Cook and Hahn (1989), Roley and Sellon also included days of regularly scheduled FO MC meetings in their sample. Moreover, instead of simply looking at observed changes in the target rate, Roley and Sellon used federal funds futures rates to estimate the element of surprise in each policy decision. Mapping their analysis back to equation (1), we would have $\mathrm{x}_{\mathrm{t}}{ }^{\prime}=\left[1, \mathrm{f}_{\mathrm{t}}{ }^{(\mathrm{u})}\right]$, where ) $\mathrm{f}_{\mathrm{t}}{ }^{(\mathrm{u})}$ denotes the difference between actual and expected values of the target rate. ${ }^{12}$

The model used in this paper differs from the traditional event-study framework in several key respects. First, I explicitly model the time-varying nature of financial market volatility; second, I allow for policy effects both on the level and variance of returns, and, third, I use all daily observations on stock returns, not just those that correspond to days of policy announcements. Nonetheless, the vector $x_{t}$ in equation (1) does incorporate a key

${ }^{12} \mathrm{O}$ ther papers that use similar estimation approaches include Bomfim and Reinhart (2000), Kuttner (1999), and Thornton (1996). 
feature of traditional event-study approach: Motivated by the monetary economics literature, $\mathrm{x}_{\mathrm{t}}$ includes a proxy for the change in the markets' perceptions of the near-term monetary policy outlook. $^{13}$

The approach used in this paper also differs in a significant way from other studies undertaken in the finance literature to assess the relationship between news and market volatility. In particular, a common approach used in this literature is to use the number of news items arriving over a given period as a proxy for the information flow hitting the markets at that point in time (e.g. Mitchell and Mulherin, 1994, Jones et al., 1998). O ne potential drawback of this methodology is that it does not control for the information content of news items and thus does not distinguish anticipated from unanticipated announcements. In this paper, I explicitly address this drawback: While I rely on an analytical framework that is widely used in the news-volatility literature, I modify it by taking steps to isolate the element of surprise in the announcements. ${ }^{14}$

\section{Data and Computation of Market-Implied Expectations}

All data are daily and run from June 1989 to D ecember 1998. The beginning of the sample is dictated by the availability of the federal funds futures data, which are used in the

${ }^{13} \mathrm{Near}$-term policy expectations are discussed in detail in the next section.

${ }^{14}$ Since writing the first draft of this paper, I have come across a recent paper by Li and Engle (1998) that also attempts to isolate the element of surprise in announcements. While I use futures prices to proxy for market participants' expectations, Li and Engle rely on survey data. 
construction of the policy expectations measure. ${ }^{15}$ Stock returns are proxied by daily percentage changes in the Standard \& Poors 500 index. I use Federal Reserve data on policy meeting dates and on the target federal funds rate. ${ }^{16}$

Mark et Partiapants' E x pectations. As discussed in section 3, the change in market participants' near-term monetary policy expectations is a potentially important element of $\mathrm{x}_{\mathrm{t}}$ in equation (1). For any given day in the sample, this variable is defined as the change in the futures rate implied by the contract set to mature at the end of the following month. As of day $\mathrm{t}$, we can write the futures rate implicit in next month's contract as

\section{(7) $\quad F_{t}^{(1)}=\left(\sum_{j=t_{1}}^{t_{m}}\left[E\left(f_{j} \mid \Omega_{t}\right)+\phi_{t}^{(j-t)}\right]\right)\left(1 /\left(t_{m}-t_{1}+1\right)\right)$}

where $t_{1}$ and $t_{m}$ are the first and last days of next month, respectively. $E\left(f_{j} \mid S_{t}\right)$ is the expected value of the Fed funds rate on day $\mathrm{j}$ conditional on information available at day $t$, and $\mathrm{R}_{\mathrm{t}}^{(\mathrm{j}-\mathrm{t})}$ is the corresponding forward premium.

Given equation (7), computing the change in near-term policy expectations is straightforward. Following Kuttner (1999), I abstract from changes in forward premiums

15 The Fed funds futures market was established in 1989 by the Chicago Board of Trade, where contracts are currently traded based on the average daily value of the federal funds rate in the current month, as well as several months ahead. Thornton (1996) provides an overview of the nature of the contract, and Krueger and Kuttner (1996) report that expectations derived from fed funds futures contracts are efficient forecasts of the funds rate.

${ }^{16} \mathrm{I}$ am interested in FOMC-meeting days to the extent that they correspond to days of scheduled monetary policy announcements. Given that there was a one-day lag between meetings and announcements in most of the pre-1994 sample, what I call an FO MC-meeting day over most of that period is actually the day after the official meeting date. 
and write

\section{(8) $\Delta F_{t}^{(1)}=\left(\sum_{j=t_{1}}^{t_{k}}\left[E\left(f_{j} \mid \Omega_{t}\right)-E\left(j, \Omega_{t-1}\right)\right]\right)\left(1 /\left(t_{m}-t_{1}+1\right)\right)$}

It is easy to see that ) $F_{t}^{(1)}$ will be positive (negative) if the information released on day t leads market participants to expect monetary policy to be tighter (easier) in the near term than had been previously thought.

An equation similar to (8) is also used in the empirical analysis to measure the element of surprise in policy announcements. As discussed in section 5, that element is measured as the appropriately scaled one-day change in the futures rate corresponding to the currentmonth contract.

\section{Estimation Results}

I estimate various versions of the general model described in section 3 using the quasi-maximum likelihood procedure discussed in Bollerslev and Wooldridge (1992). The estimated versions of all specifications discussed in this section allow for day-of-the-week effects on volatility, as well as a lagged dependent variable in the conditional mean equation. D ay-of-the-week effects are included in the equation for the scale factor $s_{t}$ so that we can, for instance, distinguish a potentially significant "Monday effect" from any pre-announcement effect--most FOMC meetings are held on Tuesdays. ${ }^{17}$ The inclusion of lagged stock returns in equation (1) is also standard in the finance literature, where a small, but statistically

${ }^{17}$ The finding of significant day-of-the-week effects on asset prices is widely reported in the literature (see, e.g., French, 1980, Jones et al., 1998, and Li and Engle, 1998) . 
significant autocorrelation coefficient is commonly reported for most asset returns (see, e.g., Jones et al, 1998).

PreA nnouncement $\mathrm{E}$ ffects. I start by estimating a model formed by equations (1) through (4) and (6), which I shall call model 1. As discussed above, model 1 allows me to test whether market volatility is systematically different on days around regularly scheduled FO MC meetings. Estimation results are reported in the first column of Table 1, where all test statistics are computed as in Bollerslev and Wooldridge (1992) and are thus robust to non-normality of $u_{t}$.

Looking at the conditional mean equation first, the estimates indicate that near-term revisions in policy expectations have a negative and statistically significant effect on stock returns: For each basis-point increase in the expected average daily value of the funds rate in the following month, daily stock market returns are reduced by 0.04 percentage point. ${ }^{18}$ In addition, the results detect a very small but significant degree of autocorrelation in stock returns.

Turning to the conditional variance equations, individual t statistics suggest that volatility is abnormally high on FO MC meeting days, but no significant effects on volatility

${ }^{18}$ The finding of a significant coefficient on the expectations revision measure stands in marked contrast with results reported in the event-study literature, which generally have found no significant short-run policy effects on daily returns--see, e.g., Roley and Sellon (1998). At least two factors help explain the difference in findings. First, I focus on all days when the market was open and not just on days of policy action, as is customary in the event-study literature. Thus, my measure of expectations revisions captures not just the market's reaction to a policy announcement, but also its reassessment of the policy outlook in light of new information extracted from economic data released on non-policy days. Second, unlike the event-study literature, I explicitly model the time-varying nature of return volatility. I plan to analyze these two factors in future work. 
are found on either the day before or the day after meetings. Moreover, the statistically significant effect on volatility of FO MC-meeting days should be interpreted with care: A Wald test for the joint hypothesis that the coefficients on all three FO MC-day dummies is zero cannot be rejected at the 10 percent significance level.

Judging from the results for model 1 , the popular notion that the markets are calmer than normal on days leading up to FO MC meetings does not appear to have empirical support. Indeed, not only there appears to be no "calm" before the storm, but one might even question whether the data support the notion of the "storm" itself--the idea that volatility is boosted on FO MC-meeting days. Model 1 suggests that days around regularly scheduled FOMC meetings are apparently just like other days and leave no statistically significant imprint on the daily volatility of stock returns.

Still, model 1 misses an important aspect of reality. As discussed in section 2, the news arrival process for monetary policy decisions changed significantly in 1994, and the FO MC's new policy disclosure practices suggest that policy-meeting days might have become more important in the eyes of market participants since then. To test for this hypothesis I replace equation (6) in model 1 with the following:

(9)

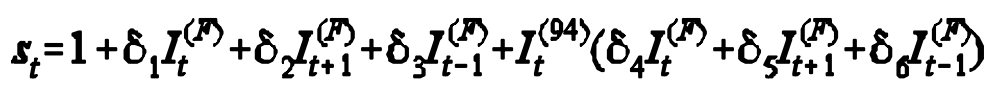

where $\mathrm{I}_{t}{ }^{(94)}$ is a dummy variable set to one on days since the beginning of 1994 and zero before then.

I shall denote the system formed by equations (1)-(4) and (9) as model 2. Equation 
(9) allows FO MC-meeting days to have different effects on volatility in the pre-1994 and post-1993 periods. Estimation results are summarized in the second column of Table 1. Consistent with our working hypothesis, individual t statistics suggest significant calmbefore-the-storm effects, in that conditional volatility is depressed on days preceding regularly scheduled post-1993 FO MC meetings--the pre-announcement effect $\left(*_{5}\right.$ is significantly negative)--and boosted, over the entire sample, on FOMC days--the news effect $\left(*_{1}\right.$ is significantly positive). Moreover, the Wald statistic for the joint hypothesis that all 3 post-1993 dummies have zero coefficients--implying no difference between the two subsamples--is rejected at the 7 percent significance level, and the Wald statistic for the joint hypothesis of no FO MC-meeting day effects across the entire 1989/ 98 sample can be rejected with 1 percent significance. Thus, model 2 provides some evidence of both preannouncement and news effects and is consistent with the calm-before-the-storm hypothesis, although pre-announcement effects are evident only after the FO MC adopted the practice of making its policy decisions mostly during the days of regularly scheduled FOMC meetings.

H ow do policy decisions affect volatility? The analysis now turns to a restricted version of model 2 and takes a closer look at the news effect, i.e., to the potentially positive effect of policy announcements on conditional volatility. I impose the following restrictions on model 2:

$$
\mathrm{HO}: *_{2}=*_{3}=*_{4}=*_{6}=0
$$

and find that they cannot be jointly rejected even at the 10 percent significance level. In 
estimating the restricted system, I also expand the coverage of the news effect to include not just days of scheduled FOMC meetings, but also all other days when the target federal funds rate was changed. The restricted model, which I shall call model 3, is formed by equations (1)-(4) and equation (10), shown below:

\section{(10) $s_{t}=1+\delta_{1} I_{t}^{(A)}+\delta_{5}\left(I_{t}^{(94)} I_{t+1}^{(I)}\right)$}

where $I_{t}^{(A)}$ is set to one on policy announcement days--defined as FO MC meeting days and other days of policy action--and zero elsewhere.

Estimation results, reported in the first column of Table 2, confirm the findings based on model 2: The pre-announcement effect is significant in the post-1993 sample-conditional volatility is about $1 / 2$ its typical level on the day before scheduled FO MC meetings--and the news effect is significant over the entire sample--conditional volatility is about 40 percent above typical levels on days of FO MC decisions. The joint hypothesis that these effects are zero can be rejected at the 1 percent significance level.

The Informational C ontent of A nnouncements. Model 3 makes no distinction between those FO MC decisions that were fully anticipated by market participants and those that were not. Y et, theory suggests that it is only the element of surprise in news releases that should affect market prices. I address this issue in model 4, which is identical to model 3, except that I replace $I_{t}{ }^{(A)}$ with the indicator variable $I_{t}{ }^{(S)}$, set to one on days of policy surprises and zero elsewhere.

\section{(11) $s_{t}=1+\delta_{1} I_{t}^{(5)}+\delta_{5}\left(I_{t}^{(94)} I_{t+1}^{(J)}\right)$}


To measure the element of surprise in the policy announcements, I rely on the methodology used and described in Kuttner (1999). In particular, I define the element of surprise on the day of the policy announcement as the appropriately scaled one-day change in the federal funds futures rate implied by the current-month contract:

\section{(12) $\Delta F_{t}^{(9)}=\gamma_{t}\left(f_{t}-E\left(f_{t} \mid \Omega_{t-1}\right)\right)$}

where ${ }_{t}$ is a deterministic function of the length and number of days remaining in the current month. ${ }^{19}$

Estimation results for model 4 are reported in the second column of Table 2. Restricting our attention to days of surprise announcements has the effect of nearly doubling the news effect relative to model 3. In particular, while the pre-announcement effect remains unchanged at about -0.49 , the magnitude of the news effect increases from 0.42 in model 3 to 0.79 in model 4 . Both effects are highly significant, with the joint hypothesis that they are zero being rejected at the 1 percent level.

Sameday Response to Scheduled vs. Unscheduled Policy A nnouncements. We have already detected one important difference in the way the stock market responds to scheduled versus unscheduled announcements: Scheduled announcements produce calm-before-the-storm effects; unscheduled announcements, by definition, do not. In addition, the fact that policy

${ }^{19}$ In theory, the right-hand side of (12) would also include a term involving changes in forward premiums. To address potential concerns about ignoring these changes, the estimation of model 4 effectively defines a surprise as a (scaled) change in the current month's futures rate in excess of 2 basis points. I have experimented with different thresholds for the definition of what constitutes a surprise and generally found that the main results are unaffected. 
decisions have been announced both on regularly scheduled FO MC days and on days between FO MC meetings allows us to test the following hypothesis: D oes the markets' same-day response to policy news vary according to whether the date of the announcement had been previously scheduled? To address this question, I modify the $s_{t}$ equation in model 4 to allow for different effects on volatility from scheduled and unscheduled announcements:

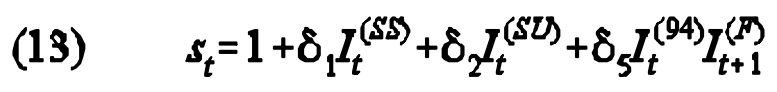

where $\mathrm{I}_{t}{ }^{(\mathrm{SS})}$ is a dummy variable set to one on days of surprise announcements released on regularly scheduled days--days of FOMC meetings--and $\mathrm{I}_{\mathrm{t}}{ }^{(\mathrm{SU})}$ is analogously defined for nonFO MC-meeting policy surprises.

Estimation results for the system formed by equations (1)-(4) and (13), labeled model 5, are reported in the second column of Table 3 . The null of no differences between the one-day responses of market volatility to scheduled and unscheduled announcements cannot be rejected at the 20 percent significance level. Therefore, the evidence suggests that uncertainty about the timing of the announcement does not appear to affect the magnitude of the announcement effect on market volatility. This result should be taken with caution, however, in that some of the days that we have labeled as days of unscheduled announcements might actually have been perceived differently by market participants. For instance, Reinhart and Simin (1997) point out that 7 of the 24 policy actions taken over the 1989-1992 period took place on days of monthly employment releases. ${ }^{20}$

${ }^{20} \mathrm{Li}$ and Engle (1998) and Anderson and Bollerslev (1998) have also examined the potentially different market reaction to scheduled and unscheduled announcements. For 
Is the $\mathrm{E}$ ffect of Policy N ews Symmetric? Thus far the analysis has assumed that policy surprises have a symmetric effect on volatility. The work of Black (1976), French, Schwert, and Stambaugh (1987), Nelson (1991), and many others suggests otherwise, implying that positive interest rate surprises--funds rate higher than expected--have a stronger effect on volatility than do negative surprises. ${ }^{21}$ To test for asymmetric policy effects, I change model 4 as follows:

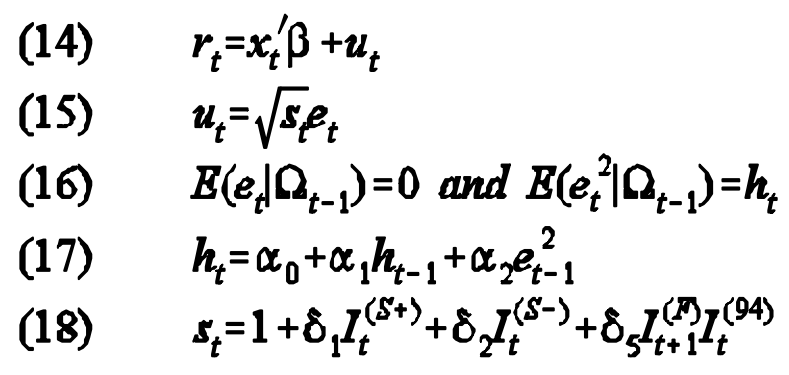

and call it model 6. Equations (15)-(17) are identical to the corresponding ones in model 4, but the conditional mean and $s_{t}$ equations are changed to explicitly allow for a asymmetric effects of policy news on the first and second moments of stock returns. In particular, $\mathrm{x}_{\mathrm{t}}$ in equation (14) is redefined to be [1, ) $\left.\left.F_{t}^{(1+)},\right) F_{t}^{(1-)}, r_{t-1}\right]^{\prime}$, where ) $F_{t}^{(1+)}$ and ) $F_{t}{ }^{(1-)}$ are vectors containing positive and negative revisions to near-term policy expectations, and $\mathrm{I}_{t}^{\left({ }^{(S)}\right)}$ and $\mathrm{I}_{t}^{\left({ }^{(-)}\right)}$

instance, Li and Engle report differing degrees of persistence in the response of volatility in the Treasury futures market to the two announcement types.

${ }^{21}$ Black suggests that the so-called leverage effect is behind this asymmetry. In particular, higher interest rates induce higher leverage ratios, which in turn increase the risk associated with holding stocks and the volatility of stock returns. An alternative explanation is the volatility-feedback effect, examined by French, Schwert and Stambaugh (1987). (Engle and $\mathrm{Ng}, 1993$, and Bollerslev, Chou, and Kroner, 1993, provide a more recent discussion of the leverage and volatility-feedback hypotheses and associated literature.) 
in equation (18) denote days of positive and negative surprises, respectively.

Estimation results are summarized in the second column of Table 4. The Wald test for the null of symmetric effects on the level of stock returns cannot be rejected at usual significance levels, but the same test for the volatility of stock returns is comfortably rejected at 5 percent significance. Thus, a positive policy surprise--an announced value for the target federal funds rate that exceeds the market's expectations--tends to boost stock market volatility in the short run by significantly more than negative surprises, a result that is consistent with the leverage and volatility-feedback hypotheses.

Relation to Previous Results R eported in the L iterature. The finding of a significant preannouncement effect in the stock market is consistent with results obtained by Jones et al. (1998) for the Treasury securities market and by Li and Engle (1998) and French et al. (1989) for the Treasury and agricultural futures market, respectively. Although reports of this phenomenon are common in the financial press, which generally attributes it to market participants' unwillingness to trade just ahead of the release of a significant piece of news, the theoretical literature has been relatively silent on this issue. The results presented in this paper reinforce the need for developing market microstructure models that explicitly allow volume, volatility, and information acquisition to interact in an environment with predetermined news arrival times.

As for the news effect, the results reported in this paper also have useful implications for broader issues in the finance literature. The small and sometimes only marginally significant effect of announcements on stock market volatility--reported for models 1 
through 3--is broadly consistent with a number of papers in the finance literature--e.g. Berry and Howe (1994) and Mitchell and Mulherin (1994). However, as discussed above, models 1 through 3 suffer from one important drawback: They failed to distinguish what was truly news in the announcements from what had already been anticipated by market participants, a failure that is also present in a surprisingly large number of papers in the literature, including the Berry-Howe and Mitchell-Mulherin articles just cited. Indeed, as suggested by the results for model 4, the news effect nearly doubled once I took steps to isolate the element of surprise in the announcement.

Lastly, the finding that policy surprises induce greater volatility is consistent with finance models that maintain that the release of public information induces greater volatility-e.g., Harris and Raviv (1993), Foster and Viswanathan (1993), and Varian (1989)--and with the existence of an asymmetric relationship between news and volatility--Black (1976), French et al. (1987), and Nelson (1991).

\section{Concluding Remarks}

In examining the relationship between the stock market and monetary policy, this paper combined two different approaches widely used in the monetary economics and finance literatures. Financial economists have long considered the effects of releases of economic data on the volatility of asset markets by examining what happens to market volatility on news arrival dates. Meanwhile, monetary economists have examined how monetary policy surprises affect the level of stock prices by relating the element of surprise in the policy decision to the change in asset prices following the announcement of the 
decision. Each camp has met with only limited success in detecting a measurable relationship between news and stock prices: Several papers in the finance literature have highlighted the weak connection between the volatility of stock prices and identifiable news releases, and a majority of studies in the monetary economics literature has been unable to detect a statistically significant relationship between one-day changes in stock prices and monetary policy surprises. This paper argues that the two literatures can learn from one another. On the one hand, the finance literature's focus on economic announcements per se, without controlling for the element of surprise in such announcements, might help explain why so many studies have failed to find a significant link between market volatility and economic news. On the other hand, by either implicitly assuming that the conditional volatility of stock returns is time invariant or by simply leaving its time-varying nature unspecified, monetary economists have failed to consider a potentially significant effect of policy surprises on the short-run behavior of the market.

The findings reported in this paper raised important questions for future work. In particular, in analyzing the market's response to scheduled and unscheduled announcements, a potentially interesting issue is whether the corresponding impulse response functions for volatility are significantly different (Li and Engle, 1998). O ther issues that also merit further consideration include a closer look at the relationship between first- and second-moment responses to policy news and the explicit analysis of risk premiums around announcement days, as in Jones et al (1998). In future work I also plan to extend the approach used in this paper to other asset markets, especially the Treasury securities market, and to use EGARCH 
models to examine the asymmetric effect of policy surprises in greater detail. Lastly, the finding of highly significant pre-announcement effects in the stock market suggests a topic that deserves closer consideration by the market microstructure literature. 


\section{References}

Andersen, Torben G. and Tim Bollerslev, 1998, Intraday activity patterns, macroeconomic announcements, and longer-run dependencies, Journal of Finanœ, 53, 219-265.

Andersen, Torben G . and Tim Bollerslev, 1997, Intraday seasonality and volatility persistence in financial markets, Journal of E mpirical Finanœ, 4, 115-158.

Berry, Thomas D . and Keith M. Howe, 1994, Public Information Arrival, Journal of Finance, 49, 1331-1346.

Black, Fischer, 1976, Studies in stock price volatility changes, Procedings of the 1976 M eetings of the A merican Statistical A ssociation, Business and E conomics Statistics Section, 177-181.

Bollerslev, Tim, 1986, Generalized autoregressive conditional heteroskedasticity, Journal of E conometrics, 31, 307-327.

Bollerslev, Tim, Ray Y. Chou, and Kenneth F. Kroner, 1993, ARCH modeling in finance: A review of the theory and empirical evidence, Journal of $\mathrm{E}$ conometrics, 52, 5-59.

Bollerslev, Tim and Jeffrey Wooldridge, 1992, Quasi-maximum likelihood estimation and inference in dynamic models with time-varying covariances, E conometric R eviews, $11,143-172$.

Bomfim, Antulio N. and Vincent R. Reinhart, 2000, Making News: Financial Market Effects of Federal Reserve D isclosure Practices, Manuscript, Federal Reserve Board.

Castanias, Richard P., II, 1979, Macroinformation and the Variability of Stock Market Prices, Journal of F inanœ, 34, 439-450. 
Chen, Carl R., Nancy J. Mohan, and Thomas L. Steiner, 1999, Discount rate changes, stock market returns, volatility and trading volume: Evidence from intraday data and implications for market efficiency, Journal of Banking and Finance, 23, 897-924.

Cook, Timothy and Thomas Hahn, 1989, The effect of changes in the federal funds rate target on market interest rates in the 1970s, Journal of M onetary E conomics, 24, 331-351.

Cutler, D avid M., James M. Poterba, and Lawrence H. Summers, 1989, What moves stock prices?, Journal of Portfolio M anagement, 15, 4-12.

Ederington, Louis H. and Jae Ha Lee, 1993, How markets process information: News releases and volatility, Journal of F inanœ 48, 1161-1191.

Engle, Robert F. and Victor K. Ng, 1993, Measuring and testing the impact of news on volatility, Journal of Finance, 48, 1749-1778.

Feinman, Joshua, 1993, Estimating the open market desk's daily reaction function, Journal of M oney, Credit, and Banking 25, 231-247.

Foster, F. D ouglas and S. Viswanathan, 1993, Variations in trading volume, return volatility and trading costs: Evidence on recent price formation models, Journal of Finanœ, 48, 187-211.

French, Kenneth R., 1980, Stock returns and the weekend effect, Journal of Financial E conomics, 8, 55-69.

French, Kenneth R., Richard Leftwich, and William Uhrig, 1989, The effect of scheduled announcements on futures markets, Manuscript, University of Chicago. 
French, Kenneth, G. William Schwert, and Robert F. Stambaugh, 1987, Expected stock returns and volatility, Journal of Financial E conomics, 19, 3-29.

Harris, Milton and Artur Raviv, 1993, D ifference of opinion make a horse race, Review of Financial Studies, 6, 473-506.

Jones, Charles M., O wen Lamont, and Robin L. Lumsdaine, 1998, Macroeconomic news and bond market volatility. Journal of Financial E conomics, 47, 315-337.

Kim, O liver and Robert E. Verrecchia, 1991, Market reaction to anticipated announcements. Journal of F inancial E conomics, 30, 272-309.

Krueger, Joel T. and Kenneth N. Kuttner, 1996, The Fed funds futures rate as a predictor of Federal Reserve policy. Journal of F utures M ark ets, 16, 865-879.

Kuttner, Kenneth N., 1999, Monetary policy surprises and interest rates: Evidence from the Fed funds futures market, Manuscript, Federal Reserve Bank of New Y ork. Li, Li and Robert F. Engle, 1998, Macroeconomic announcements and volatility of treasury futures, D epartment of Economics Discussion Paper 98-27, University of California, San D iego.

Mitchell, Mark L. and J. Harold Mulherin, 1994, The Impact of Public Information on the Stock Market, Journal of F inanœ, 49 (3), 923-950.

Nelson, D aniel B., 1991, Conditional heteroskedasticity in asset returns: A new approach, E conometrica, 59, 347-370.

Reinhart, Vincent R. and Timothy Simin, 1997, The market reaction to Federal Reserve policy action from 1989 to 1992, Journal of E conomics and Business, 49(2), 149-168. 
Roley, V. Vance and G ordon H. Sellon, Jr., 1998, Market reaction to monetary policy nonannouncements, Federal Reserve Bank of Kansas City, Research Working Paper 98-06.

Roll, Richard, 1988, R², Journal of Finanœ, 43, 541-566.

Thornton, D aniel L., 1996,. D oes the Fed's new policy of immediate disclosure affect the market? Federal Reserve Bank of St. Louis R eview, 78(6), 77-88. , Tests of the market's reaction to federal funds rate target changes, Working paper, Federal Reserve Bank of St. Louis.

Varian, Hal R., 1989, Differences of opinion in financial markets, in: Courtenay C. Stone, ed., F inancial Risk: Theory, evidence and implications, Proceedings of the E leventh A nnual E conomic Policy Conference of the F ederal Reserve Bank of St. L ouis, Boston, MA: Kluwer Academic Publishers. 


$$
\begin{aligned}
& r_{t}=\beta_{0}+\beta_{1} \Delta F_{t}^{(1)}+\beta_{2} r_{t-1}+u_{t}, \quad u_{t}=\sqrt{s_{t}} e_{t}, E\left(e_{t} \mid \Omega_{t-1}\right)=0 \text { and } E\left(e_{t}^{2} \mid \Omega_{t-1}\right)=h_{t} \\
& h_{t}=\alpha_{0}+\alpha_{1} h_{t-1}+\alpha_{2} e_{t-1}^{2} \\
& s_{t}=1+\delta_{1} I_{t}^{(J)}+\delta_{2} I_{t+1}^{(J)}+\delta_{3} I_{t-1}^{(J)}+I_{t}^{(94)}\left(\delta_{4} I_{t}^{(J)}+\delta_{s} I_{t+1}^{(J)}+\delta_{\sigma} I_{t-1}^{(I)}\right)
\end{aligned}
$$

\section{Model 1}

$$
\begin{array}{ll}
0.047 & (3.321) \\
-0.040 & (-7.612) \\
0.051 & (2.378) \\
0.005 & (2.382) \\
0.946 & (94.217) \\
0.050 & (4.966) \\
0.463 & (2.161) \\
-0.135 & (-0.861) \\
-0.052 & (-0.425)
\end{array}
$$$$
* 4
$$$$
* 5
$$$$
* 6
$$

Model 2

$0.044 \quad(3.173)$

$-0.040(-7.565)$

$0.050 \quad(2.335)$

$0.006 \quad(2.321)$

0.946 (93.376)

$0.049 \quad(4.942)$

$0.682(2.052)$

$0.041 \quad(0.182)$

$-0.135(-0541)$

$-0.474(-1.192)$

$-0.527(-2.293)$

$0.152(0.526)$

Hypothesis tests

(P-values for Wald statistics)
$* 1=* 2=* 3=0$
0.115
$* 4=* 5=* 6=0$
0.066
$*_{i}=0$, for $i=1,6$
$1.418 \mathrm{e}-12$

Note. Robust $\mathrm{t}$ - and Wald statistics are calculated using the procedure described in Bollerslev and Wooldridge (1992). Robust t-statistics are shown in parenthesis. All variables are defined in the text. $(\mathrm{N}=2414)$ 


\section{Table 2: How do policy announcements affect volatility?}

$$
\begin{aligned}
& r_{t}=\beta_{0}+\beta_{1} \Delta F_{t}^{(1)}+\beta_{2} r_{t-1}+u_{t}, \quad u_{t}=\sqrt{s_{t}} e_{t}, E\left(e_{t} \mid \Omega_{t-1}\right)=0 \text { and } E\left(e_{t}^{2} \mid \Omega_{t-1}\right)=h_{t} \\
& h_{t}=\alpha_{0}+\alpha_{1} h_{t-1}+\alpha_{2} e_{t-1}^{2} \\
& s_{t}=1+\delta_{11} I_{t}^{(A)}+\delta_{12} I_{t}^{(S)}+\delta_{S} I_{t}^{(94)} I_{t+1}^{(I)}
\end{aligned}
$$

Model 3

$0.045(3.191)$

$-0.040(-7.480)$

$0.049(2.290)$

$0.006(2.424)$

0.945 (94.494)

$0.050(5.021)$

$0.423(2.336)$

$-0.487(-7.793)$
Model 4

$0.046(3.275)$

$-0.041(-7.597)$

$0.049(2.306)$

$0.006(2.394)$

$0.946(95.324)$

$0.049(5.060)$

$0.792(2.731)$

$-0.486(-7.802)$

Hypothesis tests

(P-values for Wald statistics)
$* 11=* 5=0$
$1.387 \mathrm{e}-14$

Note. Robust $\mathrm{t}$ - and Wald statistics are calculated using the procedure described in Bollerslev and Wooldridge (1992). Robust t-statistics are shown in parenthesis. All variables are defined in the text. $(\mathrm{N}=2414)$ 


\section{Table 3: The Effects of Scheduled and Unscheduled Announcements}

$$
\begin{aligned}
& r_{t}=\beta_{0}+\beta_{1} \Delta F_{t}^{(1)}+\beta_{2} r_{t-1}+u_{t}, \quad u_{t}=\sqrt{s_{t}} e_{t}, E\left(e_{t} \mid \Omega_{t-1}\right)=0 \text { and } E\left(e_{t}^{2} \mid \Omega_{t-1}\right)=h_{t} \\
& h_{t}=\alpha_{0}+\alpha_{1} h_{t-1}+\alpha_{2} e_{t-1}^{2} \\
& s_{t}=1+\delta_{1} I_{t}^{(S S)}+\delta_{2} I_{t}^{(S S)}+\delta_{s} I_{t}^{(94)} I_{t+1}^{(S)}
\end{aligned}
$$

Model 4

$0.046(3.275)$

$-0.041(-7.597)$

$0.049(2.306)$

$0.006 \quad(2.394)$

0.946 (95.324)

0.049 (5.060)

$0.792(2.731)$

$0.792(2.731)$

$-0.486(-7.802)$
Model 5

$0.045(3.250)$

$-0.041(-7.638)$

$0.049(2.314)$

$0.006(2.366)$

$0.946(95.133)$

$0.049(5.040)$

$0.957 \quad(2.604)$

$0.308(0.940)$

$-0.485(-7.813)$

Hypothesis tests

(P-values for Wald statistics)

$$
* 1=* 2
$$

0.266

Note. Robust $\mathrm{t}$ - and Wald statistics are calculated using the procedure described in Bollerslev and Wooldridge (1992). Robust t-statistics are shown in parenthesis. All variables are defined in the text. For convenience, estimation results from model 4, first reported in Table 2, are repeated in column 1. $(\mathrm{N}=2414)$ 


\section{Table 4: Is the effect of policy announcements symmetric?}

$$
\begin{aligned}
& r_{t}=\beta_{0}+\beta_{11} \Delta F_{t}^{(1+)}+\beta_{12} \Delta F_{t}^{(1-)}+\beta_{2} r_{t-1}+u_{t}, \quad u_{t}=\sqrt{s_{t}} e_{t}, E\left(e_{t} \Omega_{t-1}\right)=0 \text { and } E\left(e_{t}^{2} \mid \Omega_{t-1}\right): \\
& h_{t}=\alpha_{0}+\alpha_{1} h_{t-1}+\alpha_{2} e_{t-1}^{2} \\
& s_{t}=1+\delta_{1} I_{t}^{(S+)}+\delta_{2} I_{t}^{(S-)}+\delta_{S} I_{t}^{(94)} I_{t+1}^{(S)}
\end{aligned}
$$

\section{Model 4}

$0.046(3.275)$

$-0.041(-7.597)$

$-0.041(-7.597)$

$0.049(2.306)$

$0.006(2.394)$

$0.946(95.324)$

$0.049(5.060)$

$0.792(2.731)$

$0.792(2.731)$

$-0.486(-7.802)$
Model 6

$0.059(3.618)$

$-0.052(-5.165)$

$-0.033(-4.883)$

$0.047 \quad(2.201)$

$0.006(2.403)$

0.945 (95.071)

$0.050(5.118)$

$1.648 \quad(2.667)$

$0.253(1.066)$

$-0.490(-8.107)$

\begin{tabular}{|c|c|}
\hline $\begin{array}{ll}\$ 11=\$ & 12 \\
* 1=* 2 & \end{array}$ & $\begin{array}{l}0.139 \\
0.034\end{array}$ \\
\hline$\$ 11=\$ 12$ and $* 1=* 2$ & 0.032 \\
\hline
\end{tabular}

Hypothesis tests

(P-values for Wald statistics)

Note. Robust $\mathrm{t}$ - and $\mathbf{W}$ ald statistics are calculated using the procedure described in Bollerslev and Wooldridge (1992). Robust t-statistics are shown in parenthesis. All variables are defined in the text. For convenience, estimation results from model 4, first reported in Table 2, are repeated in column $1 .(\mathrm{N}=2414)$ 